\title{
Bladder Papillary Urothelial Neoplasm
}

National Cancer Institute

\section{Source}

National Cancer Institute. Bladder Papillary Urothelial Neoplasm. NCI Thesaurus. Code C39857.

A neoplasm with papillary architectural pattern arising from the bladder urothelial cells. 